\title{
Attempts of PAD Teaching Methodology in Modern Chinese College English Writing Class: A Grounded Theory Based Perspective
}

\author{
Huanan $\mathrm{Su}$ \\ College of Arts and Sciences, University of the Cordilleras, Baguio City, Philippines
}

\begin{abstract}
This research paper attempts to have an in-depth understanding of PAD (presentation-assimilation-discussion) teaching methodology applied in a modern Chinese college course, which is College English Writing class, from the perspective of the Grounded Theory. Based on a detailed introduction and analysis of the Grounded Theory, this research makes efforts to answer such a question that how PAD teaching methodology is applied in modern Chinese College English Writing class as well as how it helps Chinese college students learn in their College English Writing class. The PAD teaching methodology in modern Chinese College English Writing class is a new type of teaching mode, being divided into three processes: presentation, assimilation and discussion (which is the co-called PAD). The key innovation in the PAD teaching methodology in modern Chinese College English Writing class is to stagger the lectures and discussions in time, so that students have a week time for personalized assimilation, which mobilizes students' interest in learning, promotes students' enthusiasm, cultivates students' learning autonomy, and improves the quality of the teaching of College English Writing class. As a qualitative research, this paper employs methods of literature synthesis and comparative analysis to reach such a conclusion that PAD teaching methodology does help and facilitate modern Chinese college students in their learning of College English Writing class. An important perspective from the Grounded Theory has provided a strong support to further verify the necessary role that PAD teaching methodology has played in modern Chinese College English Writing class.
\end{abstract}

Index Terms-PAD teaching methodology, College English Writing class, modern Chinese college students' language learning, a grounded theory based perspective

\section{INTRODUCTION}

The reform of college English teaching in modern China is constantly developing. College English writing teaching is highly valued in the domain of foreign language teaching in college classes. Higher requirements have been putting forward for the cultivation of college students' writing ability. College teachers' characteristics and attitudes, college students' characteristics and attitudes, the teacher-student ratio, writing strategies and activities, as well as the writing assessment will have a direct impact on college students' comprehensive writing ability.

Professor Zhang Xuexin, from Department of Psychology, School of Social Development and Public Policy, Fudan University, combines the advantages of lecture-based classrooms and discussion-based classrooms and puts forward a new idea called "The PAD Class" (Zhang, 2015), creatively reforming the Chinese traditional classroom teaching mode and fully mobilizing the enthusiasm and interest of college students, which finally improves the autonomy of modern Chinese college students' writing behavior, as well as their writing ability.

In view of this, based on a series of research literature, this research paper adopts the Grounded Theory based paradigm to conduct this exploratory research, specifically to conduct this qualitative research on the factors affecting English writing ability in the process of modern Chinese college students' English language learning. At the same time, since PAD teaching methodology is introduced within this research paper, this will definitely help us understand more about the basic principles of PAD teaching methodology (Zhang, 2018) and its application in modern Chinese College English Writing classes.

Therefore, the research paper helps us further understand the psychological processes involved in the English language learning of contemporary Chinese college students, understand the mechanism and restriction conditions of the English language learning. Nevertheless, it will also place great significance for the first and foreign language learning of contemporary Chinese college students as well as the first and foreign language teaching of contemporary Chinese college language educators.

\section{LITERATURE REVIEW}

For this part of the research paper, a review of literature will include three main components. A brief review of the Grounded Theory starts this part, followed by the introductions and analyses of the social constructivist theory and the PAD teaching methodology. 


\section{A. The Grounded Theory}

What is the Grounded Theory? The Grounded Theory is the one that is jointly developed by two scholars whose names are Anselm Strauss and Barney Glaser (1987) from Columbia University at the end of the $20^{\text {th }}$ century. Simply put, the Grounded Theory is a qualitative research method that uses a systematic procedure to develop and inductively lead a rooted theory for a certain phenomenon as well as for a series of related phenomena (Glaser, 1998).

1. Definition

The Grounded Theory (GT) is a qualitative research method whose main purpose is to establish a theory based on empirical data (Strauss \& Corbin, 1998). Researchers generally do not have theoretical hypotheses before the start of their researches, and they start directly from actual observations, summarize empirical generalizations from the original data, and then rise to a systematic theory. The Grounded Theory is actually a method of establishing a substantive theory from the bottom-up way, which is, searching for core concepts that reflect the essence of things and phenomena on the basis of systematic collection of data.

The Grounded Theory constructs relevant social theories through the connections between concepts analyzed. The Grounded Theory must be supported by empirical evidences, but its main feature is not in its empirical nature, but in that it abstracts new concepts and ideas from empirical facts. In philosophical thinking, the grounded theoretical methods are based on the paradigm of post-positivism, emphasizing the falsification of established theories. Therefore, the Grounded Theory also has a certain connection with the social constructivist theory.

2. Theory Generation

The Grounded Theory especially emphasizes the promotion of theory from data, and believes that only through in-depth analysis of data can a theoretical framework be gradually formed. This is actually a process of induction, condensing data continuously from the bottom to the top. Different from the General Grand Theory, the Grounded Theory does not make logical deductions on the hypotheses set by the researchers themselves, but conducts inductive analysis from the data instead. The theories must be traceable to the original data they produced, and they must be based on empirical facts. This is because the Grounded theorists believe that only those theories derived from data have vitality in practice. If the theory is consistent with the data, combined with the social constructivist theory, the theory will have practical uses and can be used to construct and guide people's specific life practices in their daily lives.

3. Important goals

The primary goal of the Grounded Theory is to establish a substantive theory between the Grand Theory and the micro-operational hypothesis, but it does not rule out the construction of a universal formal theory. However, formal theory must be established on the basis of substantive theory. Only after the substance theory is established on the basis of data, can the formal theory be established on the basis of various related substantive theory. This is because the Grounded Theory believes that knowledge is accumulated, and it is a process of continuous evolution from facts to substantive theory, and then to formal theory. Meanwhile, the construction of formal theory requires a large amount of data sources and the intermediary of substantive theory. For instance, if a formal theory is constructed directly from a data source, meaning that the jump is too great, and then a great number of loopholes may arise consequently.

\section{Theory Flexibility}

While using predecessor theories appropriately, the Grounded Theory believes that the researcher's personal explanations can also play an important role in constructing theories. The reason why researchers can "understand" the data is because the researchers have brought in their own empirical knowledge. The theory generated from the data is actually the result of continuous interaction and integration between the data and the researcher's personal interpretation.

We know that the use of relevant literature can broaden our horizons and provide new concepts and theoretical frameworks for data analysis, but at the same time, we must also pay attention not to use predecessor theories too much. Otherwise, the thoughts of our predecessors may constrain our thinking, causing us to consciously or unconsciously apply other people's theories to our own data. Or in other words, it is very dangerous to put your own information into other people's theories.

5. Theory as a Research Method

With regard to the choice of the Grounded Theory as a research method, since there are currently no mature theoretical hypotheses and related research in China and abroad and quantitative research methods seem to be inappropriate for the original intention of this research. Therefore, this research paper adopts the Grounded Theory as an exploratory research method, which is very important for the study of language learning of modern Chinese college students. According to Anselm Strauss and Barney Glaser (1987), as a qualitative research method, the Grounded Theory is considered to be the most influential research paradigm in the field of language acquisition researches, and it is actually at the forefront of the qualitative research revolution (Charma, 2000).

For instance, this research method aims to establish substantive theories from a large amount of English learning and English teaching experience data from college students and teachers without research hypotheses. The core lies in the use of scientific deduction, analysis, logical induction (Thomas \& James, 2006) and other methods to continuously compare and analyze the data of English learning and English teaching, and even more detailed aspects, such as the relevance of English writing, and finally to arrive at new theories.

Meanwhile, there are no more related results using the Grounded Theory research method in the domestic and foreign 
language initiation research literature. Therefore, the Grounded Theory research method is an innovation and attempt in the application of this paper. Specifically, in the research steps of the Grounded Theory method, the collection and analysis of English learning and English teaching materials are carried out simultaneously and continuously, which is reflected in every coding process.

In a nutshell, the step-by-step coding of English learning and English teaching data is the most critical link in the Grounded Theory, including three levels of coding, which are open coding, axial coding and selective coding. The research flow of the Grounded Theory is shown below in Figure 2.1.

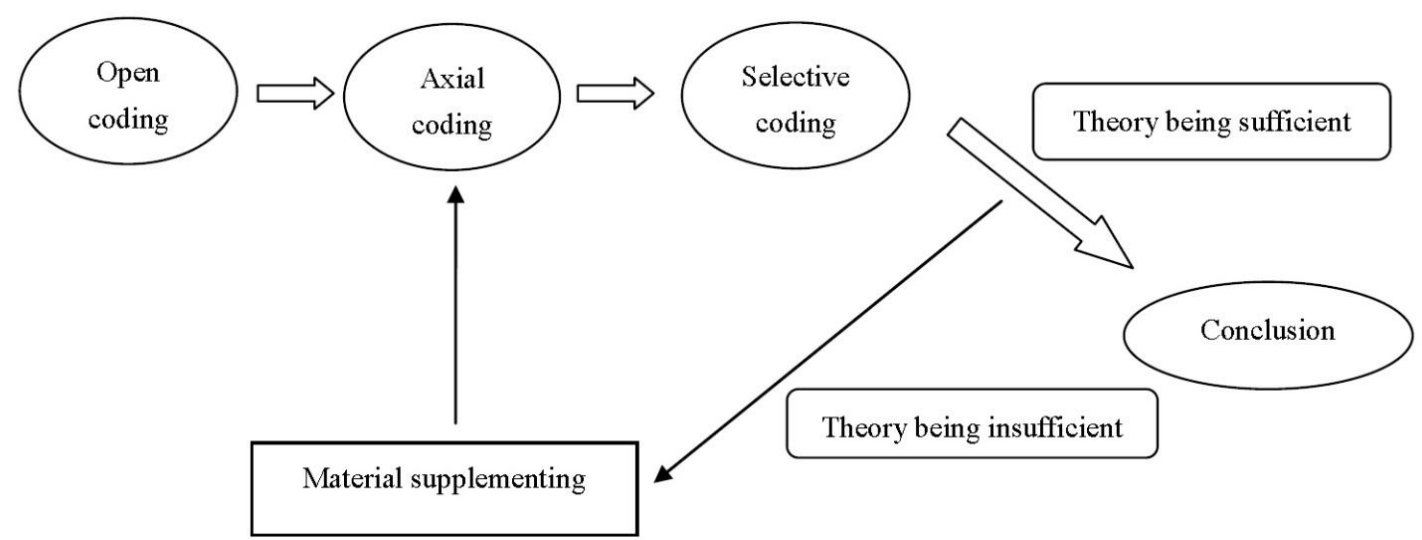

Figure 2.1 Research Flow of the Grounded Theory

\section{B. The Social Constructivist Theory}

The social constructivist theory emphasizes the importance and the role of culture and context in a developing personal interpretation and an understanding of society (Wu, 2017). Systemic-functional linguists believe that texts are produced and determined by social contexts, so that it is possible to identify the social elements from language teaching and language learning, as $\mathrm{Wu}$ (2017) interprets. Therefore, this section will analyze how the social constructivist theory is contextualized in language teaching and language learning, especially in the language learning programs. Later than that, as the two fundamental contributors to a language classroom, teachers and learners' roles and joint efforts will also be introduced in this section.

1. Theory of Language Teaching

The social constructivist approaches related to language teaching involve a large number of innovations amongst instructors' teaching in various classroom settings (Santrock, 2011). In this subsection, based on the viewpoint of social constructivist theory, the author will focus on a consolidation of knowledge about various constructivist perspectives as well as the points where the social constructivist approaches fit in the overall college English argumentation writing classroom.

From a general view, the social constructivist approach underlines the social context of language learning and the idea that knowledge is actually mutually built and constructed within a certain environment (Santrock, 2011). Language learners' involvement with other people produces chances for learners to evaluate and refine their understandings once they are exposed to the thinking of others and when they are participating in creating shared understandings in a broader social context. In this way, experiences in a social context provide an important mechanism for the further development of the learners' thinking (Johnson \& Johnson, 2010).

Vygotsky's social constructivist theory is especially relevant for the teaching of a language. Moving from Piaget to Vygotsky, the conceptual social constructivist change is from the individual to collaboration, social interaction and sociocultural activity (Daniels, 2011) (see Figure 2.2 below). In Piaget's cognitive constructivist approach, learners construct knowledge by transforming, organizing, and reorganizing their previous knowledge and information, while Vygotsky's social constructivist approach emphasizes that learners construct knowledge through social interactions with others in a broader social context (Santrock, 2011). The content of this knowledge is actually influenced by the culture in which the learners live, which includes different kinds of languages, different kinds of religious beliefs and various language skills in a broader context. 


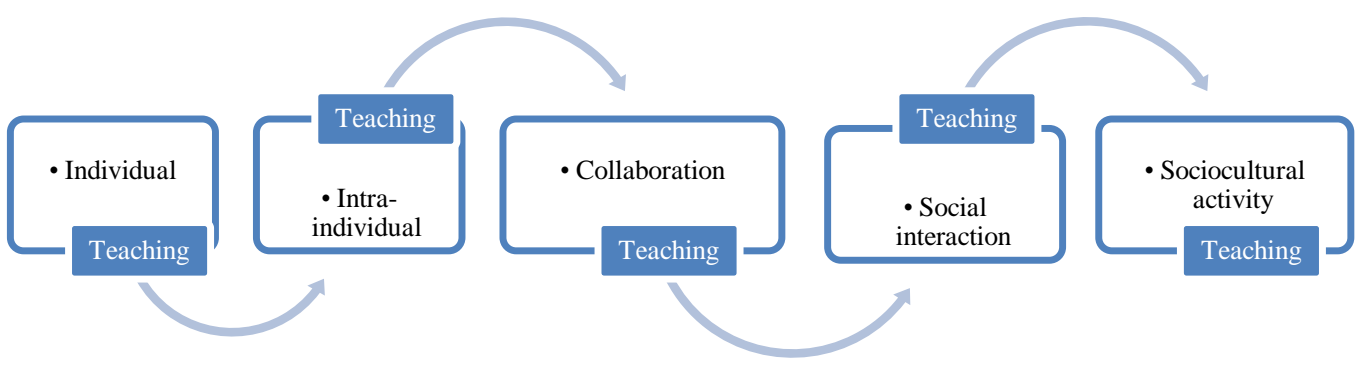

Figure 2.2 Social Constructivist Change of Language Teaching

While Piaget emphasizes that teachers should provide support for learners to explore and develop their understanding of knowledge (Santrock, 2011), Vygotsky stresses that teachers should create as many opportunities as possible for learners to learn by constructing knowledge along with the teachers and their peers. In both Piaget's and Vygotsky's conceptual theories of learning contexts, teachers are serving as facilitators and guides rather than directors and modelers in the learners' learning contexts of knowledge (Santrock, 2011).

Situated cognition refers to an important assumption in the social constructivist teaching and the idea that learners' critical thinking appears or is situated in social and physical context (Stapleton, 2001; Santrock, 2011). In other words, knowledge is involved in and connected to the context in which knowledge is learned and thus developed. As Santrock (2011) describes, if this is the case, it makes much sense to creating learning situations for the learners that are quite similar to the real-world learning environments as much as possible.

To illustrate, the Pennsylvania State University has ever conducted a study to help learners' understand volcanoes through situated cognition. In order to expand the learners' knowledge and understanding of volcanoes, some learners are placed in the role of scientists studying an active volcano; meanwhile some other learners are given the task of reporting what an emergency evacuation team is expected to do when an active volcano breaks out. As Santrock (2011) describes, using information technology and the internet resources, the "scientist" learners try to examine new stories about the basic information of an active volcano; while the "evacuation team" learners do researches for information about the impact that an active volcano has on inhabitants and how they can be removed from the danger of an erupting volcano.

2. Theory of Language Learning

The theoretical framework of the study focuses on the social constructivist theory of learning that connects with Piaget's and Vygotsky's theory, which puts emphasis on the social interaction as a necessary precursor to internalization of meaning in learning. The theory of Piaget and Vygotsky sets the platform to investigate the process of writing amongst learners to construct their knowledge in their wiring process.

In the 1960s, Piaget's work as cited by Steffe and Thompson (2000) became the basis for programs of early education that emphasized discovering learning and a supportive rather than a directive form of teaching. From the view of Piaget, the relationship between teachers' teaching and learners' learning must be carefully orchestrated for cognitive development on the part of young learners to occur (Chandler \& Jarvis, 2001). Although the majority of educators would no longer give so much weight to independent discovery as the key to learning, Piaget's conception of the learners as actively constructing their knowledge on the basis of what they have brought prior to knowledge in writing, to encounter with new information and experience has taken a firm hold and is presupposed in almost all recent work on learning and development. As is commonly acknowledged that, knowledge is not passively received either through the senses or by the way of communication; however, knowledge is actively built up by the cognizing subjects (Glasserfeld, 1995).

From the socio-cultural perspectives of learning, language is regarded as a tool of social interactions, through which learners who have skills and knowledge at a higher level assist those who are less capable in engaging in a shared activity or in solving a problem (Vygotsky, 1978; Lee, 2000). Thus, according to Vygotsky, social relationships are closely linked to the development of mental abilities as well as learning. This idea is culturally reflected in his theory of "the zone of proximal development (ZPD)", referring to "the distance between the actual developmental level as determined by in dependent problem solving and the level of potential development as determined through problem solving under adult guidance or in collaboration with more capable peers" (Vygotsky, 1978, p.86).

Vygotsky's formulation of a socio-cultural approach in learning claims that a higher mental functioning and a human action in general are mediated by technical tools and psychological signs; his focus is on the psychological aspect as opposed to the technical aspect (Lee, 2000). The complex processes of human semiotic action are proposed by him when he outlines the role of sign systems like human language, whether it is in inter-mental or in intra-mental functioning. Learning is mediated firstly on the inter-psychological plane between a person and others as well as their cultural artifacts and secondly appropriated by individuals on the intra-psychological plane (Lee, 2000).

Taking into consideration the work of Piaget and Vygotsky, it is obviously known that knowledge is not fixed, 
autonomous and dependent; rather, knowledge is constructed, reconstructed and co-constructed among learning participants in various specific situations. By utilizing the socio-cognitive and the socio-cultural resources at their disposal, learners work collaboratively towards more successful achievements goals that occur in learners' discussions and activities (see Figure 2.3 below). These two social constructivist perspectives focus on the interdependence of social and individual processes in the construction of knowledge, paving a good way to the implementation of PAD-based instruction in classroom practice.

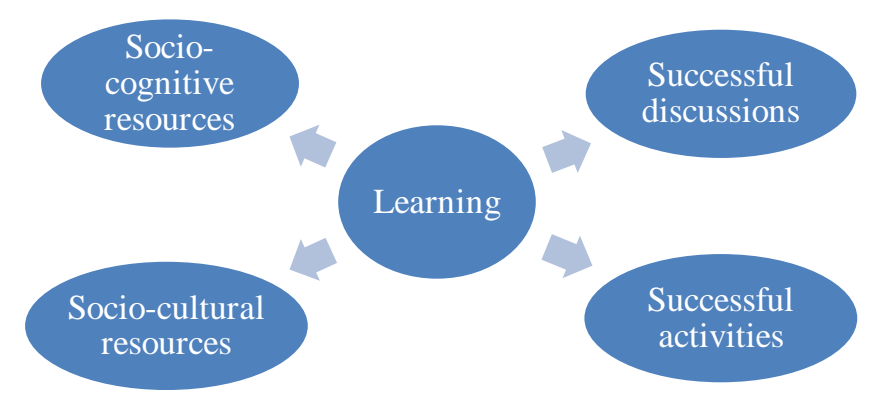

Figure 2.3 A Social Constructivist Situation of Language Learning

\section{Social Constructivist Language Learning Programs}

Language learning programs based on a social constructivist theory vary from one to another, among which there are two programs worth mentioning, referring to the Fostering a Community of Learners (FCL) and the School for Thought (SFT). These two programs will show us some ways to apply social constructivist ideas and techniques in English argumentative writing classroom successfully.

To specify, the School for Thought (SFT) learning program is another formal program of social constructivist learning program that combines aspects of the Jasper Project (JP), the Fostering a Community of Learners (FCL) and the Computer-Supported Intentional Learning Environment (CSILE) in a school learning environment. The Jasper Project, FCL and CSILE share some certain characteristics that allow them to be correlated and combine in a school language learning environment.

4. Teachers and Learners as Joint Contributors

Social constructivist approaches stress that teachers and learners can contribute to learners' learning (Bock, 1986), to name but a few, four learning tools among teachers and learners can help make this happen, namely scaffolding, cognitive apprenticeship, tutoring and collaborative learning, etc.

Scaffolding, which is closely linked to the idea of the zone of proximal development (ZPD) (Vygotsky, 1978), refers to changing the level of support from learners to teachers (Santrock, 2011). During a course of teaching section, a more skilled person, usually referring to the teacher or the advanced learner, adjusts the amount of guidance to fit the learners' current situations and performances. When the task the learner is learning is new, the teacher may use direct instruction; while the learners have learned a certain amount of knowledge and their competence also increases, the teacher would provide less guidance.

Developmental psychologists Grindstaff and Richmond (2008) have ever emphasized that an important tool for education is the cognitive apprenticeship, a technique in which an expert, namely the teacher, stretches and supports a novice's, namely the learners, understanding and use of a culture's comprehensive skills. The cognitive apprenticeship is important in classroom teaching because learners' learning benefits from teachers who think of their relationship with a student as a cognitive apprenticeship, using scaffolding and guided participation to help the learners learn as much as possible (Grindstaff \& Richmond, 2008).

Tutoring is a fundamentally cognitive apprenticeship between an expert and a novice, which is usually utilized between an adult and a kid or between a more skilled person and a less skilled one (Santrock, 2011). In reality, individual tutoring is pretty an effective way that benefits many learners, especially those who are not doing well enough in their learning of a subject or a course (Karsenty, 2010; Slavin, Madden, Chambers, \& Haxby, 2009).

Collaborative learning happens when learners work in small groups to help each other learn in a classroom setting, which has been widely used in recent years to enhance learners' learning and skills (Thurston et al., 2010). Collaborative learning groups vary in size, but generally, four is a typical number for a group building reference (Yan $\&$ Horwitz, 2008); in some cases, collaborative learning happens in just two learners. In a collaborative learning group, each learner generally learns as a certain part or unit of knowledge and skills and then teaches that part or unit to the group (Keramati, 2010).

\section{PAD Teaching Methodology}

There have been many classroom problems in Chinese colleges and universities in recent years. It is not uncommon 
for college students to skip lectures and classes. While at the same time, college teachers generally have heavy teaching burdens and great psychological pressure (Kay \& Dudley, 1998). Besides, under the impact of the Internet and new media, traditional lecture-based classrooms are even more boring, and there are constant calls for classroom reform. Professor Zhang Xuexin (2018) combines the advantages of lecture-based classrooms and discussion-based classrooms and puts forward a new idea called "PAD classroom", creatively reforming the Chinese traditional classroom teaching mode.

Similar to traditional classrooms, the PAD teaching methodology emphasizes teaching first and then learning, which saves efforts for students' assimilation (Zhang, 2015). Similar to a discussion-based classroom, the PAD teaching methodology emphasizes student to student interaction, requiring them to discuss and study independently, reducing the burden on teachers. All in all, there are mainly three sections within the PAD teaching model, including section of presentation, section of assimilation and section of discussion.

1. Presentation

Presentation is mainly completed by teachers. Teachers will explain the themes, content, background and writing skills of each unit, mainly explaining the key points and difficulties of teaching materials and students' learning materials. Students are required to pay attention to listening and understanding, and they are also required to write down the key points and difficulties during their understanding.

Based on the fact that the students may know very little about the PAD teaching methodology, the teacher in the first lesson of the first week is strongly suggested to explain to the students about the concepts and practical methods of the PAD teaching methodology, and then in the second lesson the teacher introduces the key and difficult points of the unit and arranges homework for the students.

2. Assimilation

Assimilation mainly refers to students' internalized absorption, and it is completed in one week after class. Within one week, students have to study independently, understand the content explained by the teacher in class and summarize the related content, encourage themselves to write unique analysis and to think and experience based on their further understanding.

Students also have to complete personal homework, solve after-class exercises by themselves. They are required to write the materials designated by the teacher, retell and summarize the article, and put forward their own opinions before the first lesson of next week starts.

3. Discussion

Discussion mainly refers to group discussion, which takes place in the classroom. Students are acting as the main actors while teachers' role is like guidance, their participation as a supplement. Generally, students can have groups of four, and they are required to use English throughout the whole process.

The discussion is divided into three sessions. In the first session, each group member is required to list at least two points that they think are wonderful to share with their group members; there is no limit to more. In the second session, each group member is required to pick out at least two points that they understand well and can be used to test their group members; there is also no limit to more. In the third session, each group member has to list at least two points that they cannot understand and ask for help from their group members.

At the end of the discussion, the teacher praises the wonderful part of the discussion, gives guidance and suggestions on the shortcomings, and makes comprehensive summaries.

\section{METHODOLOGY}

\section{A. Research Problem}

As a qualitative study, this research paper intends to have a detailed understanding of PAD teaching methodology employed in a modern Chinese college course, as is mentioned at the beginning of the paper, from the perspective of the Grounded Theory. Based on what has been introduced and analyzed in literature review, this research makes efforts to answer such a question that how PAD teaching methodology is applied in modern Chinese College English Writing class as well as how it helps Chinese college students learn in their College English Writing class.

Therefore, the research problem of the research paper is as follows: how is PAD teaching methodology applied in modern Chinese College English Writing class how does it help Chinese college students learn in their College English Writing class?

\section{B. Research Participants}

The author of this research has selected a total number of eighty-eight modern Chinese college students with half of them are female and another half are male from a medical university in China as the research participants. Among the selected Chinese college students, they come from the same medical university, but they have different educational backgrounds. Their current majors are different, and the language learning environments they are exposed to are also different from each other before they enter the university. Selecting college students based on such criteria is more conducive to the research in terms of the reliability and validity of this research topic.

\section{Research Site}


The author has chosen a medical university from Guangxi Province, China as the research site. In the process of conducting the research, in order to collect relevant data more directly and objectively, the research was carried out at the same research site from the beginning to the end. This is also aimed at providing a more convenient and objective environment for data research as well as data analysis in the later stage of the research.

\section{Research Methods}

Qualitative methods are employed to carry out this research. To specify, two analytical methods including the method of literature synthesis and the method of comparative analysis are introduced as follows.

1. Method of Literature Synthesis

The literature synthesis method is the most basic method used in this research. The author has read extensively domestic and foreign books and papers on the Grounded Theory and the PAD teaching methodology, especially those of Professor Zhang Xuexin's methodological thoughts in modern Chinese language classroom teaching. This will make the research as theoretical and original as possible.

At the same time, the author reads and analyzes through a qualitative means in order to analyze the related Grounded Theory and the teaching concepts of PAD teaching methodology more realistically and rationally, and extract the view that the Grounded Theory and PAD teaching methodology are closely integrated to a certain extent. By synthesizing a large number of relevant documents and data, the author strives to demonstrate that the analysis processes and conclusions are comprehensive and objective enough.

2. Method of Comparative Analysis

The comparative analysis method is also adopted for the research. On the one hand, this method can comprehensively sort out some necessary thoughts of the Grounded Theory and unify these scattered thoughts into a systematic and complete theory. The related theories of instructional studies are compared with the related theories of Professor Zhang Xuexin, so as to have a deeper understanding of the progresses of PAD teaching methodology.

The use of comparative analysis methods is more conducive for the author of this paper to accurately analyze the application of PAD teaching methodology in modern Chinese college students' language learning in the $21^{\text {st }}$ century, and to locate the role of PAD teaching methodology in their College English Writing class.

Besides, this paper also draws on relevant content from other disciplines such as philosophy and sociology, and adopts interdisciplinary research methods, which will definitely help to fully understand the relationship between the Grounded Theory and PAD teaching methodology in modern Chinese college students' foreign language learning.

Undoubtedly, the analytical methods mentioned above will lay a solid theoretical and methodological foundation for the research and writing of this paper. It will also provide a necessary and important premise for the writing of the findings which will be shown in the following section.

\section{FINDINGS}

\section{A. College English Writing Class for Modern Chinese College Students}

Analyses and summaries of relevant literatures of this research paper clearly show that the course of College English Writing occupies a certain position among the courses taken by modern Chinese college students. The College English Writing course aims to train, cultivate and improve the English writing ability of modern Chinese college students. At the same time, this course also tries to eliminate college students' fear of writing in English language, so that they will understand how to find opinions, how to organize opinions, and how to make sentences. In the end, through this important course of College English Writing, modern Chinese college students will be able to successfully write compositions with clear thinking, rigorous argumentations, and accurate languages.

As the core part of the College English Writing course, its main content mainly includes helping college students express clear and strict thinking in the form of "arguments + evidences" during their writing.

In general, the focus of the College English Writing class is to firstly introduce the requirements of paragraph arguments writing. Secondly, it will introduce consistency and coherence and transition of different writing paragraphs. Then, in the implementation process of College English Writing, the skills of word selection and sentence formation will be treated as the key objects of the course. Finally, through the previous relevant knowledge learned, modern Chinese college students will be able to rationally conceive an English writing framework, modify an English writing idea, and finally create high-quality English writing results.

\section{B. PAD Teaching Methodology in Modern Chinese College English Writing Class}

Based on the reviews and analyses of the related literature, it is clearly shown that PAD teaching methodology can free modern Chinese college students from rote memorization and reduce test pressure, as well as make the classroom atmosphere freer and livelier (Seow, 2002). The PAD teaching methodology can fully mobilize the enthusiasm of both college teachers and college students, significantly reduce the classroom teaching burden on college teachers, and highly achieve good teaching qualities for college teachers.

College English Writing is one of the compulsory courses for modern Chinese college students in China. Its teaching purpose is to cultivate modern college students' English writing comprehension ability and logical thinking ability. One of the important tasks of this course is to guide college students to master various writing methods and improve the 
accuracy of understanding and the speed of writing in the exam of National College English Test Band 4 and 6 (CET 4 $\& 6$ ). Based on the fact that modern college students already have a foundation in English, there are three processes in the application of PAD teaching methodology in the course of College English Writing.

1. Presentation: Listen and Take Notes

Presentation is mainly completed by college teachers. Teachers will explain the themes, content, background and writing skills of each writing unit, mainly explaining the key points and difficulties of writing materials and students' learning materials. Students are required to pay attention to listening and understanding, and they are also required to write down the key points and difficulties of the writing materials during their understanding.

Based on the fact that the students may know very little about the PAD teaching methodology, the teacher in the first lesson of the first week is strongly suggested to explain to the students about the concepts and practical methods of the PAD teaching methodology, and then in the second lesson the teacher introduces the key and difficult points of the writing unit and arranges writing homework for the college students.

2. Assimilation: Think and Write

Assimilation mainly refers to college students' internalized absorption, and it is completed in one week after class. Within one week, students have to study independently, understand the writing content explained by the teacher in writing class and summarize the related content, encourage themselves to write unique analysis and to think and experience based on their further understanding of the writing materials. Students also have to complete personal homework, solve after-class writing exercises by themselves. They are required to write the materials designated by the teacher, retell and summarize the article, and put forward their own opinions through writing before the first lesson of next week starts.

3. Discussion: Speak and Test

Discussion mainly refers to group discussion of their writing tasks, which takes place in the classroom. Students are acting as the main actors while teachers' role is like guidance, their participation as a supplement.

Generally, students can have groups of four, and they are required to use English throughout the whole process. The discussion is divided into three sessions. In the first session, each group member is required to list at least two points that they think are wonderful in their learning of writing to share with their group members; there is no limit to more. In the second session, each group member is required to pick out at least two points that they understand well in their writing learning and can be used to test their group members; there is also no limit to more. In the third session, each group member has to list at least two writing points that they cannot understand and ask for help from their group members. At the end of the discussion, the teacher praises the wonderful part of the discussion of writing, gives guidance and suggestions on the shortcomings, and makes comprehensive summaries in terms of the writing materials.

\section{CONCLUSION AND RECOMMENDATIONS}

In general, attempts of PAD teaching methodology in College English Writing class divide the whole writing class into two sections, which is not necessarily an absolute division. Based on the concepts of the Grounded Theory as well as the social constructivist theory, in the application of PAD teaching methodology, modern Chinese college students are the main body while the teacher is playing the role of a leader.

The purpose of PAD teaching methodology in the College English Writing class is to fully experience modern Chinese college students' role in the learning process and to improve their own learning autonomy and enthusiasm, which meets the initial needs of the social constructivist theory. Attempts of PAD teaching methodology act as an upsurge of classroom reform suitable for modern Chinese college teaching after the flipped classroom.

Therefore, the PAD teaching methodology in College English Writing class will definitely further help modern Chinese college students continuously improve their comprehensive ability in college English writing, so as to better prepare for the National College English Test Band 4 and 6 (CET 4 \& 6 ) and to achieve satisfactory results.

\section{ACKNOWLEDGEMENTS}

The author of this research paper wishes to thank the participants as well as the current and past investigators and staff for their contribution to the research.

\section{DECLARATION OF CONFLICTING INTERESTS}

The author of this research paper declares no potential conflicts of interest with respect to the research, the authorship, and/or the publication of this research paper.

\section{REFERENCES}

[1] Bock, J. K. (1986). Syntactic Persistence in Language Production. Cognitive Psychology, 18: 355-387.

[2] Chandler, E., \& Jarvis, M. (2001). Angels on Psychology. Cheltenham: Nelson Thornes Limited.

[3] Charma, Z. K. (2000). Grounded Theory: Objectivist and Constructivist Methods. Thousand Oaks, CA: Sage.

[4] Daniels, H. (2011). Vygotsky and Psychology: Wiley-Blackwell Handbook of Childhood Cognitive Development (2 ${ }^{\text {nd }}$ ed.). New York: Wiley Blackwell. 
[5] Glaser, B. G. (1998). Doing Grounded Theory: Issues and Discussions. Mill Valley, CA: Sociology Press.

[6] Glasserfeld, E. V. (1995). Radical constructivism: A way of knowing and learning. Washington, D.C.: Falmer Press.

[7] Grindstaff, K., \& Richmond, G. (2008). Learners' perceptions of the roles of peers in a research experience: Implications for the apprenticeship process, scientific inquiry, and collaborative work. Journal of Research in Science Teaching, 45, 251-272.

[8] Johnson, D. R., \& Johnson, F. P. (2010). Joining Together. (10 ${ }^{\text {th }}$ ed.). Upper Saddle River, NJ: Prentice Hall.

[9] Karsenty, R. (2010). Nonprofessional mathematics tutoring for low-achieving students in secondary schools: A case study. Educational Studies in Mathematics, 74, 1-21.

[10] Kay, H., \& Dudley, E. T. (1998). Genre: What Teachers Think. ELT Journal, 52(4), 308- 314.

[11] Keramati, M. (2010). Effect of cooperative learning on academic achievement of physics course. Journal of Computers in Mathematics and Science Teaching, 29, 155-173.

[12] Lee, C. D. (2000). Signifying in the zone of proximal development. In C. D. Lee \& P. Smagorinsky (Eds.), Vygotskian Perspectives on Literacy Research: Constructing Meaning through Collaborative Inquiry. Cambridge: Cambridge University Press, 191-255.

[13] Santrock, J. W. (2011). Educational Psychology ( $5^{\text {th }}$ ed.). New York: McGraw-Hill.

[14] Seow, A. (2002). The Writing Process and Process Writing. Cambridge: Cambridge University Press.

[15] Stapleton, P. (2001). Critical Thinking in Japanese L2 writing: Rethinking tired constructs. ELT Journal, 56(3), $250-257$.

[16] Steffe, L., \& Thompson, P. (2000). Teaching experiment methodology: Underlying principles and essential elements. In A. E. Kellry \& R. A. Lesh (Eds.), Handbook of research design in mathematics and science education. Mahwah, NJ: Lawrence Erlbaum Associates, 267-306.

[17] Strauss, A., \& Corbin, J. (1998). Grounded theory methodology: An overview. In N. K. Denzin \& Y. S. Lincoln (Eds.), Strategies of Qualitative Inquiry. Thousand Oaks, CA: Sage, 158-183.

[18] Strauss, A., \& Glaser, B. (1987). Grounded Theory Methodology: An Overview. Thousand Oaks, CA: Sage.

[19] Thomas, G., \& James, D. (2006). Reinventing Grounded Theory: Some Questions about Theory, Ground and Discovery. British Educational Research Journal, 32(6):767-795.

[20] Vygotsky, L. S. (1978). Mind in Society. Cambridge, MA: Harvard University Press.

[21] Vygotsky, L. S. (1978). Mind in society: The development of higher psychological processes. Cambridge, MA: Harvard University Press.

[22] Wu, Y. (2017). Reading for Writing-The Application of Genre Analysis in College English Writing in China. Theory and Practice in Language Studies, 7(10), 883-891.

[23] Yan, X., \& Horwitz, E. K. (2008). Learners' Perceptions of How Anxiety Interacts With Personal and Instructional Factors to Influence Their Achievement in English: A Qualitative Analysis of EFL Learners in China. Language Learning, 58(1): 151-183.

[24] Zhang, X. (2015). The PAD Class: a new paradigm for university classroom teaching. Society of Photo-optical Instrumentation Engineers. Society of Photo-Optical Instrumentation Engineers (SPIE) Conference Series.

[25] Zhang, X. (2018). The PAD Class: The New Wisdom of Chinese Education in the Classroom. Beijing: Science Press.

Huanan Su, male, born on 1987-08-03, from Puning City, Guangdong Province, China, is the author of this research paper. Su has earned his master's degree in English Language Teaching Methodology from Henan University, Henan Province, China in 2014. At present, $\mathrm{Su}$ is a Ph.D. student taking English Language Studies (ELS) in College of Arts and Sciences, University of the Cordilleras, Baguio City, Philippines.

Huanan $\mathrm{Su}$ is also a Chinese university lecturer mainly responsible for teaching subject of College English for Chinese university students. Besides, he also teaches subjects such as College English Writing, Vocational College English, Comprehensive Medical English (ESP), Postgraduate English Course, etc. Su's academic research area is English Language Teaching (ELT); specifically he is interested in Teaching of English as a Foreign/Second Language (TEFL/TESL). 